\title{
Catalyst Repurposing Sequential Catalysis by Harnessing Regenerated Prolinamide Organocatalysts as Transfer Hydrogenation Ligands
}

\author{
Frederic Bourgeois, ${ }^{\dagger}$ Jonathan A. Medlock, ${ }^{\star}$ Werner Bonrath,${ }^{\star}$ Christof Sparr ${ }^{*} \dagger$ \\ ${ }^{\dagger}$ Department of Chemistry, University of Basel, St.-Johanns Ring 19, 4056 Basel, Switzerland \\ *DSM Nutritional Products Ltd., P.O. Box 2676, 4002 Basel, Switzerland \\ Supporting Information Placeholder
}

\begin{abstract}
A catalyst repurposing strategy based on a sequential aldol addition and transfer hydrogenation giving access to enantiomerically enriched $\alpha$-hydroxy- $\gamma$-butyrolactones is described. The combination of a stereoselective, organocatalytic step followed by an efficient catalytic aldehyde reduction induces an ensuing lactonization to provide enantioenriched butyrolactones from readily available starting materials. By capitalizing from the capacity of prolineamides to act both as organocatalyst and transfer hydrogenation ligand, catalyst repurposing allowed the development of an operationally simple, economic and efficient sequential catalysis approach.

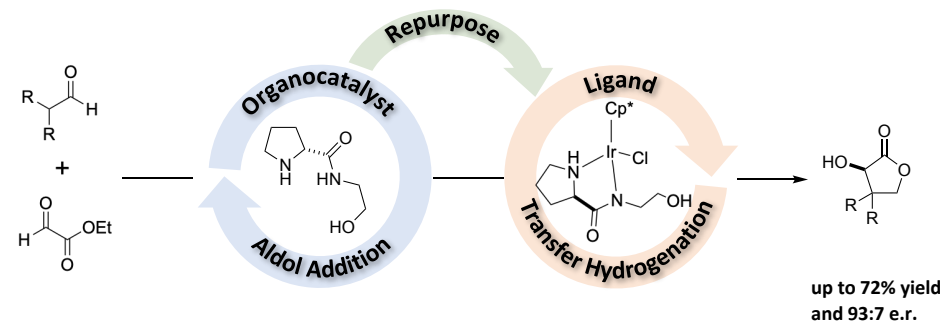

- Catalyst repurposing for sequential catalysis

- Stereoselective aldol addition/transfer hydrogenation/lactonization sequence

- Efficient and scalable synthesis of enantioenriched $\alpha$-hydroxy- $\gamma$-butyrolactones
\end{abstract}

The combination of multiple distinct catalytic transformations in a one-pot reaction procedure enables cost- and time-efficient processes towards complex targets from readily available starting materials. Especially the interplay between organo- and transition metal catalysis can provide unique possibilities for the formation of valuable organic frameworks. ${ }^{1}$ In relay, tandem or cascade catalysis, a common intermediate is released from the first catalytic cycle that directly enters a second one. This requires high reagent compatibility, which can often be circumvented by a sequential catalysis approach where after completion of the first catalytic event, reagents or catalysts required for the second transformation are added. This permits an increased scope and allows more variation of reaction conditions. ${ }^{2}$ Since amines, ${ }^{3} \mathrm{NHCs}^{4}$ and phosphines ${ }^{5}$ are frequently used both as organocatalysts and ligands, we became intrigued by the prospects of a repurposing strategy where the first catalyst upon regeneration is converted into the second by the addition of a metal precatalyst (Scheme 1a). This in situ catalyst repurposing sequential catalysis strategy (CRSC) would thus constitute a particularly effective method for a wide range of transformations. We recognized prolineamides as an ideal compound class for CRSC as they have been successfully used as organocatalysts in stereoselective cross aldol reactions ${ }^{6}$ and as ligands in transfer hydrogenations. ${ }^{7}$ We hence envisioned to exploit the proline amide derivatives in CRSC for the stereoselective synthesis of $\alpha$-hydroxy- $\gamma$-butyrolactones $\mathbf{1}$, first as catalyst of a stereoselective aldol addition to intermediate $\mathbf{2}$ and after repurposing, as ligand to promote the aldehyde reduction which induces a lactonization (Scheme 1b).
Scheme 1. Schematic Overview of Catalyst Repurposing Sequential Catalysis (CRSC)
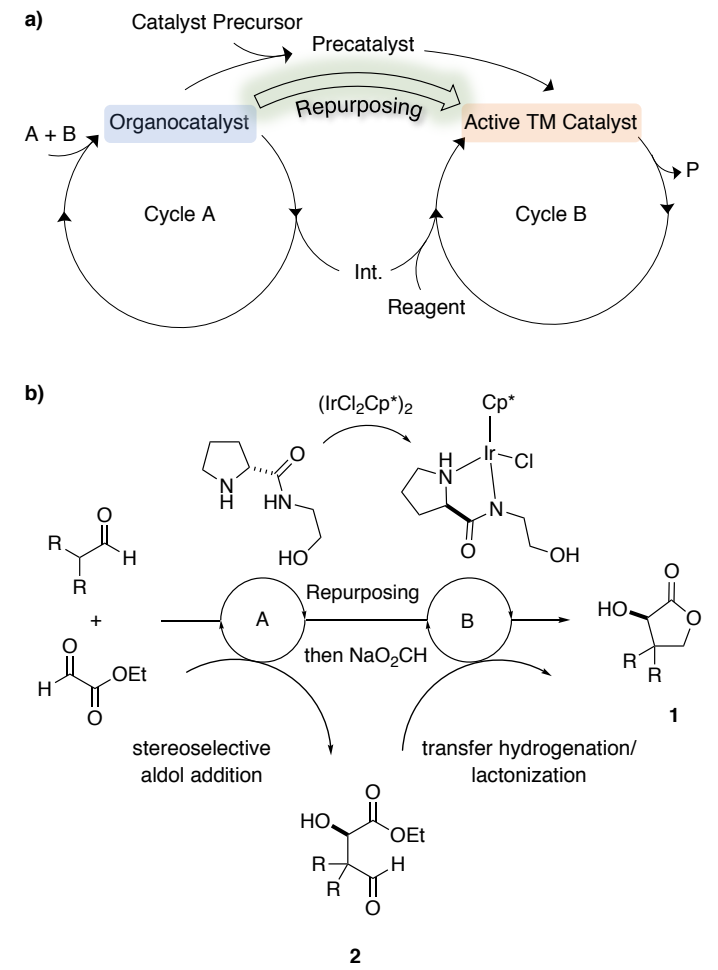
Enantioenriched $\alpha$-hydroxy- $\gamma$-butyrolactones $\mathbf{1}$ are key industrial intermediates, ${ }^{8}$ chiral auxiliaries ${ }^{9}$ and building blocks for the synthesis of biologically active compounds and natural products. ${ }^{10}$ Their previous preparation typically involved resolution protocols ${ }^{8,11}$ or a stepwise stereoselective catalysis strategy. ${ }^{12}$ Interestingly, $(R)$-pantolactone $1 \mathbf{a}(\mathrm{R}=\mathrm{Me})$, the key intermediate for the synthesis of vitamin $\mathrm{B}_{5}$ (pantothenic acid) was prepared by a one-pot combination of organo- and biocatalysts by Gröger, Berkessel and coworkers. ${ }^{13}$ We thus initiated our catalyst repurposing study by preparing $(R)$-pantolactone 1a using the regenerated amine catalyst as ligand for a transfer hydrogenation. To identify catalysts, solvents, additives and conditions suitable for both steps in the sequence, we first individually evaluated their effect on stereoselectivity and reactivity for the aldol addition and reduction (details of this prerequisite optimization are provided in the SI).

Table 1. Catalyst Repurposing Sequential Catalysis Design ${ }^{a}$

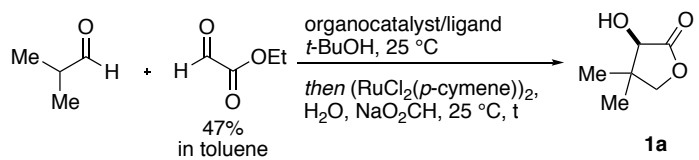

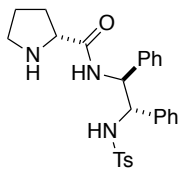

3

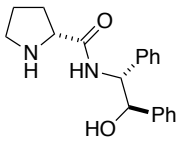

6

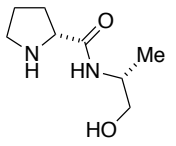

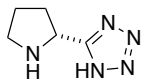
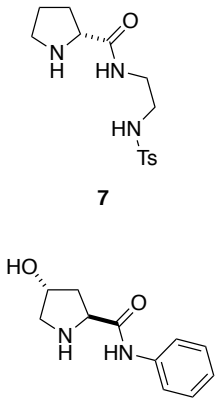

10
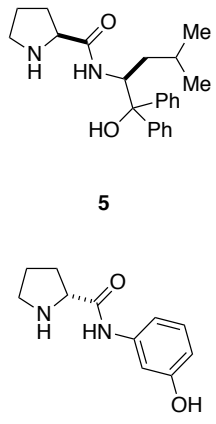

8

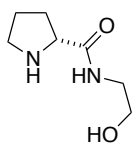

11

\begin{tabular}{|c|c|c|c|c|c|}
\hline entry & $\begin{array}{l}\text { catalyst/ } \\
\text { ligand, }\end{array}$ & $\begin{array}{l}\left(\mathrm{RuCl}_{2}(p-\right. \\
\text { cymene }))_{2}\end{array}$ & $\begin{array}{l}\mathrm{t} \\
{[\mathrm{h}]}\end{array}$ & $\begin{array}{l}\text { conv. } \\
{[\%]^{b}}\end{array}$ & e.r. \\
\hline 1 & $\mathbf{3}, 10 \mathrm{~mol} \%$ & $2.5 \mathrm{~mol} \%$ & 18 & 99 & $82: 18$ \\
\hline 2 & $4,10 \mathrm{~mol} \%$ & $2.5 \mathrm{~mol}^{\circ} \%$ & - & - & - \\
\hline 3 & $5,10 \mathrm{~mol} \%$ & $2.5 \mathrm{~mol} \%$ & - & - & - \\
\hline 4 & $\mathbf{6}, 10 \mathrm{~mol} \%$ & $2.5 \mathrm{~mol}^{\%} \%$ & 18 & 99 & $79: 21$ \\
\hline 5 & $7,10 \mathrm{~mol} \%$ & $2.5 \mathrm{~mol} \%$ & 18 & 99 & $85: 15$ \\
\hline 6 & $\mathbf{8}, 20 \mathrm{~mol} \%$ & $2.5 \mathrm{~mol} \%$ & 18 & 99 & $84: 16$ \\
\hline 7 & $\mathbf{9}, 10 \mathrm{~mol} \%$ & $1.0 \mathrm{~mol}^{\%} \%$ & 18 & 99 & $85: 15$ \\
\hline 8 & $\mathbf{1 0}, 10 \mathrm{~mol} \%$ & $1.0 \mathrm{~mol} \%$ & 2 & 99 & $19: 81$ \\
\hline 9 & $11,5.0 \mathrm{~mol} \%$ & $1.0 \mathrm{~mol} \%$ & 4 & 99 & $86: 14$ \\
\hline
\end{tabular}

${ }^{a}$ Reaction conditions: isobutanal $(0.40 \mathrm{mmol})$, ethyl glyoxalate $(0.40$ mmol, $47 \mathrm{wt} . \%$ in toluene), organocatalyst (5.0 - $20 \mathrm{~mol} \%), t-\mathrm{BuOH}$ $(0.4 \mathrm{~mL}), 25{ }^{\circ} \mathrm{C}, 24-48 \mathrm{~h}$, TM precursor $(1.0-2.5 \mathrm{~mol} \%)$, sodium formate $(2.00 \mathrm{mmol})$, water $(1 \mathrm{~mL}), 25{ }^{\circ} \mathrm{C}, 2-18 \mathrm{~h} .{ }^{b}$ Conversion determined by $\mathrm{GC}$ analysis.
Intriguingly, initial results allowed to identify a hybrid between Noyori's TsDPEN ligand and D-proline $(R)-\mathbf{3}$ as suitable catalyst and ligand (Table 1$)^{14}$ and $t$ - $\mathrm{BuOH}$ as compatible solvent. More specifically, upon completion of the enantioselective aldol addition after 24 hours, water, $\left(\mathrm{RuCl}_{2}(p \text {-cymene })\right)_{2}$ and sodium formate $\left(\mathrm{NaO}_{2} \mathrm{CH}\right)$ were added, ${ }^{15-17}$ providing $(R)$-pantolactone after $18 \mathrm{~h}$ with a $99 \%$ conversion for both steps and an e.r. of $82: 18$. We next confirmed the requirement of the amide moiety by using pyrrolidinyl tetrazole $(R)-\mathbf{4}$, which provided the expected unreduced aldol addition product. We further examined ethylene diamine or ethanolamine derivatives $(R)-5-7$ and observed that also the hydroxy terminated $(R)-6$ acts as suitable ligand for the transfer hydrogenation. With a 3-aminophenol derived catalyst $(R)-\mathbf{8}$, the effect of the different amide residues on the rate of the aldol addition step was noticeable, requiring $20 \mathrm{~mol} \%$ catalyst loading and prolonged reaction times. Structural simplification revealed, that also $(R)-9$ is suitable for CRSC, even with a reduced $\left(\mathrm{RuCl}_{2}(p \text {-cymene })\right)_{2}$ loading of 1.0 mol\% (entry 7). Interestingly, $(S)$-10 led to complete aldehyde reduction and lactonization within two hours at $25^{\circ} \mathrm{C}$ and confirmed that a $(S)$-configured catalyst provides $(S)$-pantolactone. Intriguingly, the ethanolamine derived prolinamide $(R)-\mathbf{1 1},{ }^{14 \mathrm{~b}}$ which is readily available on large scale, provided $(R)$-pantolactone 1a with a reduced catalyst/ligand loading of $5.0 \mathrm{~mol} \%$ and $1.0 \mathrm{~mol} \%\left(\mathrm{RuCl}_{2}(p \text {-cymene })\right)_{2}$ within four hours for the transfer hydrogenation step.

To further refine the CRSC, we next studied the effect of different transition metal precursors, their loading and the optimal temperature for the transfer hydrogenation step (Table 2).

Table 2. Effect of Transition-Metal Precursors ${ }^{a}$

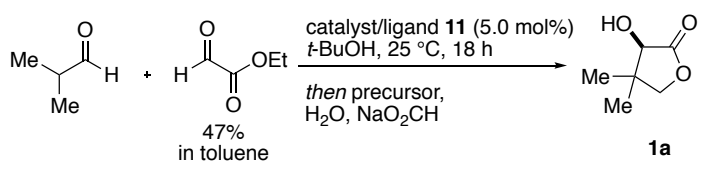

\begin{tabular}{|c|c|c|c|c|c|}
\hline entry & precursor & $\begin{array}{l}\text { precursor } \\
\text { loading }\end{array}$ & $\begin{array}{l}\mathrm{T} \\
{\left[{ }^{\circ} \mathrm{C}\right]}\end{array}$ & $\begin{array}{l}\mathrm{t} \\
{[\mathrm{h}]}\end{array}$ & $\begin{array}{l}\text { conv. } \\
{[\%]^{b}}\end{array}$ \\
\hline 1 & $\begin{array}{l}\left(\mathrm{RuCl}_{2}(p-\right. \\
\text { cymene }))_{2}\end{array}$ & $0.50 \mathrm{~mol} \%$ & $\mathrm{rt}$ & 26 & 98 \\
\hline 2 & $\begin{array}{l}\left(\mathrm{RuCl}_{2}(p-\right. \\
\text { cymene }))_{2}\end{array}$ & $0.50 \mathrm{~mol} \%$ & 40 & 6 & $98^{c}$ \\
\hline 3 & $\begin{array}{l}\left(\mathrm{RuCl}_{2}(p-\right. \\
\text { cymene }))_{2}\end{array}$ & $0.50 \mathrm{~mol} \%$ & 60 & 1 & 94 \\
\hline 4 & $\begin{array}{l}\left(\mathrm{RuCl}_{2}(\text { ben- }\right. \\
\text { zene }))_{2}\end{array}$ & $0.50 \mathrm{~mol} \%$ & 40 & 5 & 92 \\
\hline 5 & $\left(\mathrm{RhCl}_{2} \mathrm{Cp}^{*}\right)_{2}$ & $0.50 \mathrm{~mol} \%$ & 40 & 2.5 & 97 \\
\hline 6 & $\left(\mathrm{IrCl}_{2} \mathrm{Cp}^{*}\right)_{2}$ & $0.50 \mathrm{~mol} \%$ & 40 & 1 & 99 \\
\hline 7 & $\left(\mathrm{IrCl}_{2} \mathrm{Cp}^{*}\right)_{2}$ & $0.50 \mathrm{~mol} \%$ & $\mathrm{rt}$ & 4 & 99 \\
\hline 8 & $\left(\mathrm{IrCl}_{2} \mathrm{Cp}^{*}\right)_{2}$ & $0.25 \mathrm{~mol} \%$ & 40 & 2 & 93 \\
\hline 9 & $\left(\mathrm{IrCl}_{2} \mathrm{Cp}^{*}\right)_{2}$ & $0.10 \mathrm{~mol} \%$ & 40 & 5 & 99 \\
\hline
\end{tabular}

${ }^{a}$ Reaction conditions: isobutanal $(0.40 \mathrm{mmol})$, ethyl glyoxalate $(0.40$ mmol, $47 \mathrm{wt} . \%$ in toluene), organocatalyst (5.0 mol\%), $t$-BuOH $(0.4$ $\mathrm{mL}), 25-60{ }^{\circ} \mathrm{C}, 18 \mathrm{~h}$, TM precursor $(0.1-0.5 \mathrm{~mol} \%)$, sodium formate $(2.00 \mathrm{mmol})$, water $(1 \mathrm{~mL}), 25{ }^{\circ} \mathrm{C}, 1-26 \mathrm{~h} .{ }^{b}$ Conversion determined by $\mathrm{GC}$ analysis. ${ }^{c}$ scale-up to gram-scale $(30 \mathrm{mmol})$ provides $1 \mathrm{a}$ with $62 \%$ isolated yield and an e.r. of 86:14. 
With a $\left(\mathrm{RuCl}_{2}(p \text {-cymene })\right)_{2}$ precursor loading of $0.50 \mathrm{~mol} \%$, the aldehyde reduction required 26 hours to reach near completion, while increasing the temperature to $40^{\circ} \mathrm{C}$ allowed to reduce the reaction time to six hours. Satisfyingly, the catalyst-repurposing sequential catalytic reaction under these conditions was also readily applicable on gram-scale $(30 \mathrm{mmol})$ providing $(R)$-pantolactone (1a) in an overall 62\% yield and an enantiomeric excess of 86:14 (see SI for details). The reaction time could be further decreased to $1 \mathrm{~h}$ at $60{ }^{\circ} \mathrm{C}$ and a slight increase in reactivity was observed with $\left(\mathrm{RuCl}_{2} \text { (benzene) }\right)_{2}$, with almost full conversion after $5 \mathrm{~h}$ at $40^{\circ} \mathrm{C}$. An even more significant change in reactivity was observed when the transition metal was changed to rhodium, with almost full conversion after only $2.5 \mathrm{~h}$ at $40^{\circ} \mathrm{C}$, and iridium with complete conversion in less than $1 \mathrm{~h}$. Even when the precursor loading was decreased to only $0.1 \mathrm{~mol} \%$, full conversion could be achieved within $5 \mathrm{~h}$ at $40{ }^{\circ} \mathrm{C}$. With the optimal catalyst/ligand $(R)-\mathbf{1 1}$ and reaction conditions for the CRSC established, we evaluated the scope for a variety of $\alpha$-disubstituted aldehydes (Table 3 ). For the synthesis of $(R)$-pantolactone 1a, the optimized conditions led to a stereoselective aldol addition, transfer hydrogenation, lactonization sequence with an overall yield of $62 \%$ and $86: 14$ enantiomeric enrichment. Other alkyl chains for products $\mathbf{1 b}$ and $\mathbf{1 c}$ gave enantioselectivities of 81:19 e.r. and 70:30 e.r., respectively. Notably, a change to cycloalkyl substituents significantly increased product selectivity to enantiomeric ratios of up to $93: 7$ for the cyclobutyl product 1d. Corresponding five- and sixmembered derivatives 1e (e.r. 92:8) and 1f were also effectively prepared from commercially available starting materials by the catalyst repurposing sequential catalysis. However, a further increase in ring size (1g) or the introduction of an aromatic substituent (1h) impacted the yield or the selectivity. Over the course of our studies, a kinetic resolution during the transfer hydrogenation for a further enrichment of the enantiopurity was not observed and aldehyde substrates with different $\alpha$-substituents, for which low diastereoselectivities were observed, represent a current limitation of the method (see SI for details).

Table 3. Substrate Scope of the Catalyst Repurposing Sequential Catalysis for $\alpha$-Hydroxy- $\gamma$-butyrolactones ${ }^{a}$

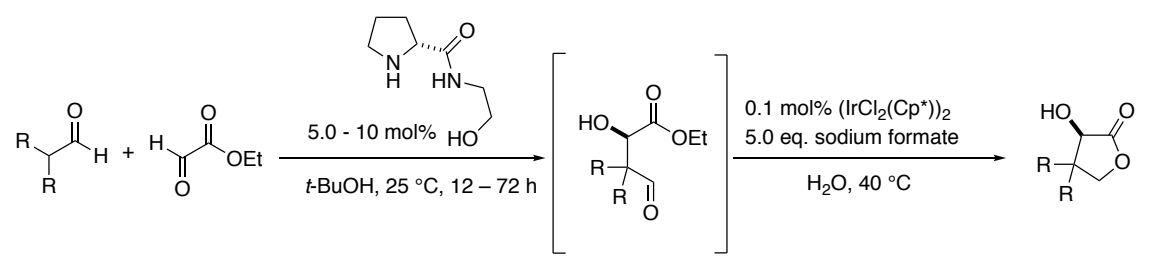

\begin{tabular}{|c|c|c|c|c|c|c|c|}
\hline entry & product & yield $[\%]^{\mathrm{d}}$ & e.r. & entry & product & yield [\%] ${ }^{\mathrm{d}}$ & e.r. \\
\hline 1 & $\begin{array}{c}\mathrm{Me} \\
\mathbf{M e} \\
\mathbf{1 a}\end{array}$ & $\begin{array}{c}62 \\
{[84]}\end{array}$ & $86: 14$ & 5 & $1 e$ & $\begin{array}{c}73 \\
{[85]}\end{array}$ & $92: 8$ \\
\hline 2 & $\begin{array}{l}\mathrm{Et}+1 \\
\mathbf{1 b}\end{array}$ & $\begin{array}{c}45 \\
{[92]}\end{array}$ & $81: 19$ & 6 & 1f & $\begin{array}{c}72 \\
{[95]}\end{array}$ & $88: 12$ \\
\hline 3 & $\begin{array}{r}\mathrm{Bu}+ \\
\mathbf{1 c}\end{array}$ & $\begin{array}{c}67 \\
{[29]^{\mathrm{e}}}\end{array}$ & $70: 30$ & $7^{b}$ & $1 \mathrm{~g}$ & $\begin{array}{c}18 \\
{[22]}\end{array}$ & $72: 28$ \\
\hline 4 & 1d & $\begin{array}{c}71 \\
{[92]}\end{array}$ & $93: 7$ & $8^{c}$ & 1h & $\begin{array}{c}64 \\
{[85]}\end{array}$ & $62: 38$ \\
\hline
\end{tabular}

${ }^{a}$ Reaction conditions: isobutanal $(1.00 \mathrm{mmol})$, ethyl glyoxalate $(1.00 \mathrm{mmol}, 47 \mathrm{wt} . \%$ in toluene $), 11(5.0-10 \mathrm{~mol} \%), t-\mathrm{BuOH}(1.0 \mathrm{~mL}), 25{ }^{\circ} \mathrm{C}, 18$ - $72 \mathrm{~h},\left(\operatorname{IrCl}_{2}\left(\mathrm{Cp}^{*}\right)\right)_{2}(0.1 \mathrm{~mol} \%)$, sodium formate $(2.00 \mathrm{mmol})$, water $(1 \mathrm{~mL}), 40{ }^{\circ} \mathrm{C}, 15 \mathrm{~h}$, isolated yield. ${ }^{b} 500 \mu \mathrm{mol}$ scale. ${ }^{c} 100 \mu \mathrm{mol} \mathrm{scale} .{ }^{\mathrm{d}} \mathrm{Yield}$ in brackets corresponds to isolated aldehyde intermediate. ${ }^{\mathrm{e}} 5.0 \mathrm{~mol} \% \mathbf{1 1}$ were used. ${ }^{\mathrm{f}} 10 \mathrm{~mol} \% \mathbf{1 1}$ were used. 
The proposed mechanism of the sequential catalytic transformation involves a first enamine formation from catalyst $(R)$ 11 and isobutanal (Scheme 2) as confirmed by NMR when equimolar amounts of the catalyst in $t$-BuOD-d10 were added under similar conditions to the $\alpha$-disubstituted aldehyde substrate (see SI for details). Monitoring the enantioselectivity over the course of the subsequent aldol addition reaction revealed only marginal variation, indicating the absence of a competitive uncatalyzed background reaction. Furthermore, a non-linear effect was not noticeable when catalyst 11 with different enantiomeric purities was employed. The catalytic cycle $\mathrm{A}$ is then closed by hydrolysis, the secondary amine catalyst is regenerated and the aldol addition intermediate in place for the transfer hydrogenation cycle $\mathrm{B}$. The addition $\left(\mathrm{IrCl}_{2} \mathrm{Cp}^{*}\right)_{2}$ allows to repurpose the regenerated prolinamide $(R)-11$ as a ligand and upon addition of sodium formate, reduces intermediate 2 to induce a direct lactonization giving the enantioenriched $\alpha$-hydroxy- $\gamma$-butyrolactones. Having observed the remarkable activity of this transfer hydrogenation system, the Ir-complex 12 was prepared by a stoichiometric addition of ligand $(R)-\mathbf{1 1}$ and $\mathrm{Et}_{3} \mathrm{~N}$ to $\left(\mathrm{IrCl}_{2} \mathrm{Cp}^{*}\right)_{2}$, which allowed to confirm its structure by X-Ray crystallography (see SI for details). ${ }^{18}$ Further studies regarding the influence of the hydroxy arrangement are currently ongoing.

\section{Scheme 2. Mechanistic Proposal}

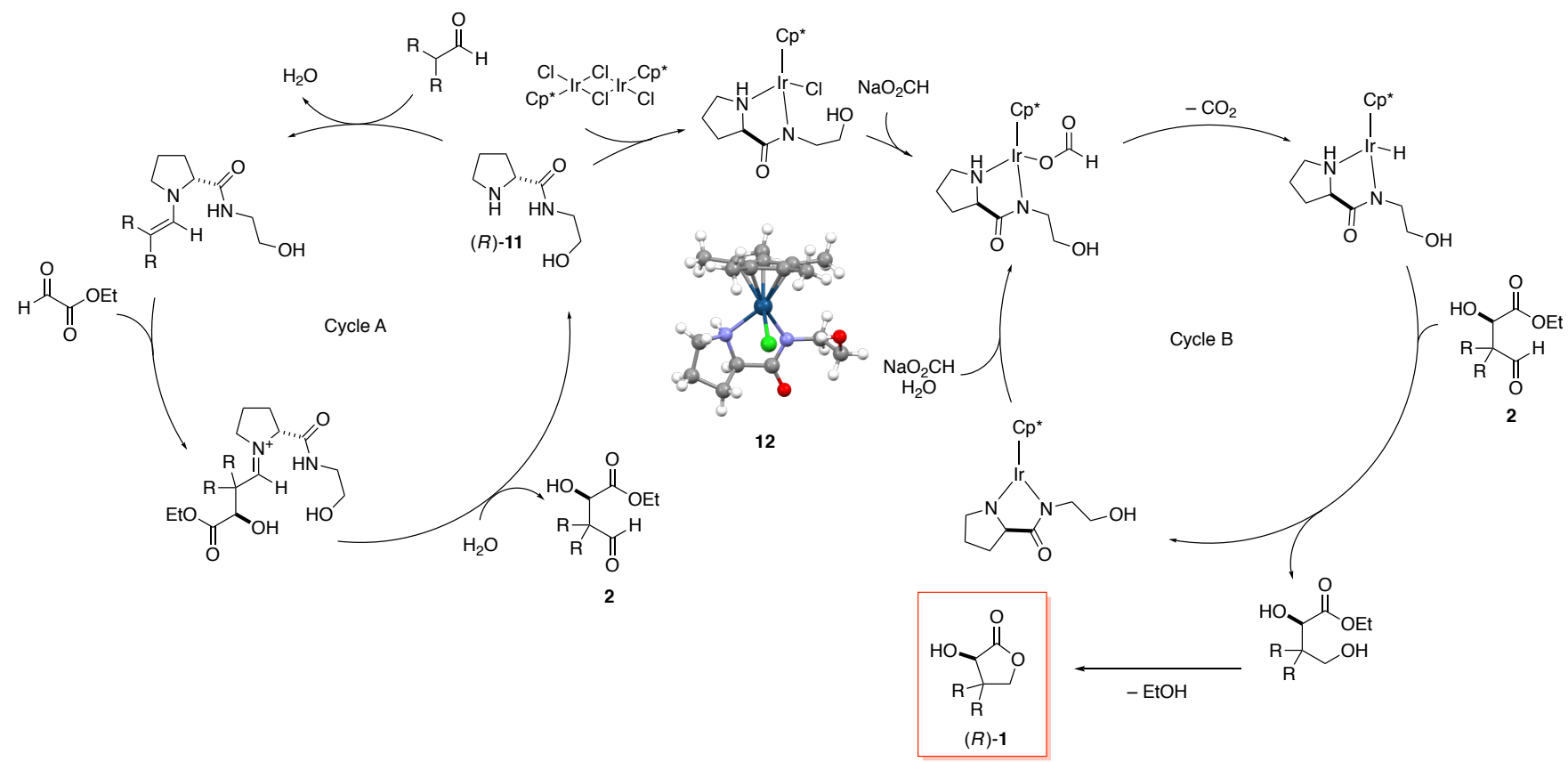

In conclusion, a catalyst repurposing sequential catalysis (CRSC) strategy was developed and employed in the preparation of enantioenriched $\alpha$-hydroxy- $\gamma$-butyrolactones by an economic and operationally simple protocol. The prolinamide organocatalyst was thereby first used in a stereoselective cross aldol addition and subsequently repurposed as ligand for a transition-metal catalyzed transfer hydrogenation. The later addition of the transition-metal precursor upon aldol addition thus allowed to utilize otherwise incompatible aldehyde substrates, which underscores in this scenario the assets of sequential catalysis in comparison with relay, tandem or cascade catalysis. Key industrial intermediates such as the vitamin $\mathrm{B}_{5}$ precursor $(R)$-pantolactone were readily available in enantioenriched form directly from commercially available starting materials. Considering the multitude of conceivable sequential reactions using amine, NHC and phosphine organocatalysts poised to be repurposed as ligands upon their regeneration, CRSC represents a fascinating possibility for the design of efficient catalytic reaction sequences.

\section{Supporting Information}

Experimental procedures and analytical data for the synthesized compounds, including ${ }^{1} \mathrm{H}$ and ${ }^{13} \mathrm{C}$ NMR spectra and HPLC data.
The Supporting Information is available free of charge on the ACS Publications website.

\section{AUTHOR INFORMATION}

\section{Corresponding Author}

*E-mail: christof.sparr@unibas.ch

\section{Author Contributions}

The manuscript was written through contributions of all authors. All authors have given approval to the final version of the manuscript.

\section{Notes}

The authors declare no competing financial interest. Patent applications were filed by DSM.

\section{ACKNOWLEDGMENT}

We gratefully acknowledge DSM Nutritional Products for financial support, Dr. Alessandro Prescimone ${ }^{\dagger}$ for X-ray crystallography, Sylvie Mittelheisser ${ }^{\dagger}$ and Dr. Michael Pfeffer ${ }^{\dagger}$ for HR-MS services and PD Dr. Daniel Häussinger ${ }^{\dagger}$ for NMR assistance. 


\section{REFERENCES}

(1) (a) Chen, D. F.; Han, Z. Y.; Zhou, X. L.; Gong, L. Z. Asymmetric Organocatalysis Combined with Metal Catalysis: Concept, Proof of Concept, and Beyond. Acc. Chem. Res. 2014, 47, 2365. (b) Shao, Z.; Zhang, H. Combining transition metal catalysis and organocatalysis: a broad new concept for catalysis. Chem. Soc. Rev. 2009, 38, 2745. (c) Du, Z.; Shao, Z. Combining transition metal catalysis and organocatalysis - an update. Chem. Soc. Rev. 2013, 42, 1337. (d) Zhong, C.; Shi, X.; When Organocatalysis Meets Transition-Metal Catalysis. Eur. J. Org. Chem. 2010, 2999.

(2) (a) Tang, C. K.; Zhou, Z. Y.; Xia, A. B.; Bai, L.; Liu, J.; Xu, D. Q.; Xu, Z. Y.; Combining Organocatalysis and Iodine Catalysis: One-Pot Sequential Catalytic Synthesis of Chiral Spirodihydrobenzofuran Pyrazolones and Spirodihydrobenzofuran Oxindoles. Org. Lett. 2018, 20, 5840. (b) Beligny, S.; Eibauer, S.; Maechling, S.; Blechert, S.; Sequential Catalysis: A Metathesis/Dihydroxylation Sequence. Angew. Chem. Int. Ed. 2006, 45, 1900. (c) Müller, J. J. T.; Debnar, T.; Menche, D.; Sequential Catalysis Involving Metal-Catalyzed Cycloisomerizations and Cyclizations (Ch. 12); Sequential Catalysis for the Stereoselective Synthesis of Complex Polyketides (Ch. 14). In Molecular Catalysts; Gade, L. H.; Hofmann, P.; John Wiley \& Sons, Ltd. 2014; pp 255 - 280; pp 299-312.

(3) Dalko, P. I. Comprehensive Enantioselective Organocatalysis: Catalysts, Reactions, and Applications.; Wiley-VCH 2013.

(4) Flanigan, D. M.; Romanov-Michailidis, F.; White, N. A.; Rovis, T. Organocatalytic Reactions Enabled by N-Heterocyclic Carbenes. Chem. Rev. 2015, 115, 9307. (b) Huynh, H. V. The Organometallic Chemistry of N-heterocyclic Carbenes; John Wiley \& Sons Ltd.; 2017, pp. 1 - 334. (c) for an elegant dual purpose, synergistic catalysis approach, see: Guo, C.; Janssen-Müller, D.; Fleige, M.; Lerchen, A.; Daniliuc, C. G.; Glorius, F.; Mechanistic Studies on a Cooperative NHC Organocatalysis/Palladium Catalysis System: Uncovering Significant Lessons for Mixed Chiral $\mathrm{Pd}(\mathrm{NHC})\left(\mathrm{PR}_{3}\right)$ Catalyst Design, J. Am. Chem. Soc. 2017, 139, 4443.

(5) (a) Guo, H.; Fan, Y. C.; Sun, Z.; Wu, Y.; K, O. Phosphine Organocatalysis Chem. Rev. 2018, 118, 10049. (b) Ni, H.; Chan, W. L.; Lu, Y. Chem. Rev. 2018, 118, 9344. (c) Fernández-Pérez, H.; Etayo, P.; Panossian, A.; Vidal-Ferran, A.; Phosphine - Phosphinite and Phosphine - Phosphite Ligands: Preparation and Applications in Asymmetric Catalysis. Chem. Rev. 2011, 111, 2119. (d) Pereira, M. M.; Calvete, M. J. F.; Carrilho, R. M. B.; Abreu, A. R. Synthesis of binaphtyl based phosphines and phosphite ligands. Chem. Soc. Rev. 2013, 42, 6990

(6) (a) Tang, Z.; Jiang, F.; Cui, X.; Gong, L. Z.; Mi, A. Q.; Jiang, Y. Z.; Wu, Y. D. Enantioselective direct aldol reactions catalyzed by L-prolinamide derivatives. PNAS 2004, 101, 5755. (b) Tang, Z.; Yang, Z. H.; Chen, X. H.; Cun, L. F.; Mi, A. Q.; Jiang, Y. Z.; Gong, L. Z. A Highly Efficient Organocatalyst for Direct Aldol Reactions of Ketones with Aldehydes. J. Am. Chem. Soc. 2005, 127, 9285.

(7) (a) Wang, D.; Astruc, D. The Golden Age of Transfer Hydrogenation. Chem. Rev. 2015, 115, 6621. (b) Denizalti, S.; Mercan, D.; Sen, B.; Gökce, A. G.; Cetinkaya, B. Asymmetric transfer hydrogenation reaction in water: Comparison of chiral proline amide/amine ruthenium(II) complexes. J. Organomet. Chem. 2015, 779, 62. (c) Rhyoo, H. Y.; Yoon, Y. A.; Park, H. J.; Chung, Y. K. Use of amino amides derived from proline as chiral ligands in the ruthenium(II)catalyzed transfer hydrogenation reaction of ketones. Tetrahedron Lett. 2001, 42, 5045.

(8) Eggersdorfer, M.; Laudert, D.; Létinois, U.; McClymont, T.; Medlock, J.; Netscher, T.; Bonrath, W. One Hundred Years of Vitamins - A Success Story of the Natural Sciences. Angew. Chem. Int. Ed. 2012, 51, 12960 .

(9) (a) Poll, T.; Sobzack, A.; Hartmann, H.; Helmchen, G. Diastereoface-Discriminative Metal Coordination in Asymmetric Synthesis: D-Pantolactone as Practical Chiral Auxiliary for Lewis Acid Catalyzed Diels-Alder Reactions. Tetrahedron Lett. 1985, 26, 3095. (b) Camps, P.; Munoz-Torrero, D. Synthesis and Applications of $(R)-$ and (S)-Pantolactone as Chiral Auxiliaries. Curr. Org. Chem. 2004, 8,1339
(10) (a) Winterbottom, R.; Clapp, J. W.; Miller, W. H.; English, J. P.; Roblin Jr., R. O. Studies in Chemotherapy. XV. Amides of Pantoyltaurine. J. Am. Chem. Soc. 1947, 69, 1393. (b) King, T. E.; Stewart, C. J.; Cheldelin, V. H. $\beta$-Aletheine and Pantetheine. J. Am. Chem. Soc. 1953, 75, 1290. (c) Nicolaou, K. C.; Dolle, R. E. Total Synthesis of Elfamycins: Aurodox and Efrotomycin. 1. Strategy and Construction of Key Intermediates. J. Am. Chem. Soc. 1985, 107, 1691. (d) Fischer, G. C.; Turakhia, R. H.; Morrow, C. J. Irreducible Analogues of Mevaldic Acid Coenzyme A Hemithioacetal as Potential Inhibitors of HMG-CoA Reductase. Synthesis of Carbon-Sulfur Interchanged Analogue of Mevaldic Acid Panthetheine Hemithioacetal. J. Org. Chem. 1985, 50, 2011. (e) De Brabander, J.; Vanhessche, K.; Vandewalle, M. Bryostatins: The Asymmetric Synthesis of $\mathrm{C}_{1}-\mathrm{C}_{9}$ and $\mathrm{C}_{11}$ $\mathrm{C}_{16}$ Fragments. Tetrahedron Lett. 1991, 32, 2821.

(11) (a) Paust, J.; Pfohl, S.; Reif, W.; Schmidt, W. Racematspaltung von Pantolacton mit neuen chiralen Aminen. Liebigs Ann. Chem. 1978, 1024. (b) Major, R. T.; Finkelstein, J. Resolution of dl$\alpha$-hydroxy- $\beta, \beta$-dimethyl- $\gamma$-butyrolactone. J. Am. Chem. Soc. 1941, 63, 1368. (c) Clark, R. W.; Deaton, T. M.; Zhang, Y.; Moore, M. I.; Wiskur, S. L. Silylation-Based Kinetic Resolution of $\alpha$-hydroxy Lactones and Lactams. Org. Lett. 2013, 15, 6132. (d) Akhani, R. K.; Clark, R. W.; Yuan, L.; Wang, L.; Tang, C.; Wiskur, S. L. Polystyrene-Supported Triphenylsilyl Chloride for the Silylation-Based Kinetic Resolution of Secondary Alcohols. ChemCatChem 2015, 7, 1527. (e) Nakata, K.; Gotoh, K.; Ono, K.; Futami, K.; Shiina, I. Kinetic Resolution of Racemic 2-Hydroxy- $\gamma$-butyrolactones by Asymmetric Esterification Using Diphenylacetic Acid with Pivalic Anhydride and a Chiral Acyl-Transfer Catalyst. Org. Lett. 2013, 15, 1170. (f) Haughton, L.; Williams, J. M. J.; Zimmermann, J. A. Enzymatic kinetic resolution of pantolactone: relevance to chiral auxiliary chemistry. Tetrahedron: Asymmetry 2000, 11, 1697. (g) Kurono, N.; Kondo, T.; Wakabayashi, M.; Ooka, H.; Inoue, T.; Tachikawa, H.; Ohkuma, T. Enantiomer-Selective Carbamylation of Racemic $\alpha$ Hydroxy- $\gamma$-Lactones with Chiral $\mathrm{Cu}^{\mathrm{II}}$ Catalysts: An Example of a Highly Active Lewis Acid Catalyzed Reaction. Chem. Asian. J. 2008, 3, 1289. (h) Shimizu, S.; Kataoka, M.; Honda, K.; Sakamoto, K. Lactone-ring-cleaving enzymes of microorganisms: their diversity and applications. J. Biotechnol. 2001, 92, 187. (i) Kataoka, M.; Nomura, J.; Shinohara, M.; Nose, K.; Sakamoto, K.; Shimizu, S. Purification and Characterization of a Novel Lactonohydrolase from Agrobacterium tumefaciens. Biosci. Biotechnol. Biochem. 2000, 64, 1255. (j) Baumann, M.; Hauer, B. H.; Bornscheuer, W. T. Rapid screening of hydrolases for the enantioselective conversion of 'difficult-to-resolve' substrates. Tetrahedron: Asymmetry 2000, 11, 4781.

(12) (a) Evans, D. A.; Wu, J.; Masse, C. E.; MacMillan, D. W. C. A General Method for the Enantioselective Synthesis of Pantolactone Derivatives. Org. Lett. 2002, 4, 3379. (b) Pansare, S. V.; Bhattacharyya, A. Enantioselective synthesis of $\beta, \beta$-dialkyl- $\alpha$ hydroxy- $\gamma$-butyrolactones. Tetrahedron Lett. 2001, 42, 9265. (c) Eliel, E. L.; Bai, X.; Ohwa, M. Enantioselective Syntheses of Substituted $\gamma$-Butyrolactones. J. Chin. Chem. Soc. 2000, 47, 63. (d) Blandin, V.; Carpentier, J. F.; Mortreux, A. Asymmetric Hydrogenation of 2,4-Dioxo Esters: Selective Synthesis of 2-Hydroxy-4-oxo Esters and Direct Access to Chiral 2-Hydroxy-4-butyrolactones. Eur. J. Org. Chem. 1999, 1787. (e) Nakano, T.; Oh-hashi, N.; Ino, Y.; Nagai, Y. Two-Step Synthesis of $\alpha$-Hydroxy- $\gamma$-Substituted $\gamma$-Lactones Via $\mathrm{Ru}(\mathrm{II})$-Catalyzed Addition of Trimethylsilyl $\alpha$ Polychlorocarboxylates or its Parent Acids to Olefins. Main Group Metal Chem. 2000, 23, 259. (f) Kallmerten, J.; Gould, T. J. AuxiliaryDirected Diastereoselectivity in the Claisen Rearrangement of Glycolate Esters. J. Org. Chem. 1986, 51, 1152. (g) Paetow, M.; Ahrens, H.; Hoppe, D. Chiral $\alpha, \omega$-Dioxy-Carbanions from 1,3-Propandiol and 1,4-Butanediol by Sparteine-Assisted Deprotonation. Enantioselective Synthesis of 1,3- and 1,4-Diols, $(R)$-Pantolactone, and a Cyclopropane. Tetrahedron Lett. 1992, 33, 5323. (h) Rao, A. V. R.; Rao, S. M.; Sharma, G. V. M. Asymmetric Synthesis of (R)-3,3-Dimethyl2-hydroxy- $\gamma$-butyrolactone en route to the Formal Synthesis of Calcium D-pantothenate. Tetrahedron Lett. 1994, 5735. (i) Upadhya, T. T.; Gurunath, S.; Sudalai, A. A new and short enantioselective synthesis of $(R)$-pantolactone. Tetrahedron: Asymmetry 1999, 10, 2899. (j) Effenberger, F.; Eichhorn, J.; Roos, J. Enzyme Catalyzed Addition 
of Hydrocyanic Acid to Substituted Pivaldehydes - A Novel Synthesis of (R)-Pantolactone. Tetrahedron: Asymmetry 1995, 6, 271. (k) Markert, M.; Scheffler, U.; Mahrwald, R. Asymmetric Histidine-Catalyzed Cross-Aldol Reactions of Enolizable Aldehydes: Access to Defined Configured Quaternary Stereogenic Centers. J. Am. Chem. Soc. 2009, 131, 16642. (1) Ojima, I.; Kogure, T.; Terasaki, T. Effective Biomimetic Route to D-(+)-Pantothenate Using Asymmetric Hydrogenation Catalyzed by a Chiral Rhodium Complex in the Key Step. J. Org. Chem. 1978, 43, 3444. (m) Roucoux, A.; Devocelle, M.; Carpentier, J. F.; Agbossou, F.; Mortreux, A. Highly Efficient Asymmetric Hydrogenation of Activated und Unactivated Ketones Catalyzed by Rhodium(I) Aminophosphine- and Amidophosphine-Phosphinite Complexes. Beneficial Effect of the Non Chiral Ligand. Synlett 1995, 4, 358. (n) Lanzilotta, R. P.; Bradley, D. G.; McDonald, K. M. Microbial Reduction of Ketopantoyl Lactone to Pantoyl Lactone. Appl. Microbiol. 1974, 1, 130. (o) Nakamura, K.; Kondo, S.; Kawai, Y.; Ohno, A. Asymmetric Reduction of Ketopantolactone by Baker's Yeast. Tetrahedron: Asymmetry 1993, 4, 1253. (p) Man-man, J.; Jinjin, W.; Zhi-Guo, L.; Zhen-mei, G. Synthesis of D-pantolactone via Combined a Novel Organocatalyst Catalyzed Asymmetric Aldol Reaction and Hydrogenation Catalyzed by $\mathrm{Cu}-/ \mathrm{SiO}_{2}$. Am. J. Appl. Chem. 2017, 5, 62 .

(13) Heidlindemann, M.; Hammel, M.; Scheffler, U.; Mahrwald, R.; Hummel, W.; Berkessel, A.; Gröger, H. Chemoenzymatic
Synthesis of Vitamin B5-Intermediate $(R)$-Pantolactone via Combined Asymmetric Organo- and Biocatalysis. J. Org. Chem. 2015, 80, 3387.

(14) (a) Manville, C. V.; Docherty, G.; Padda, R.; Wills, M.; Application of Proline-Functionalised 1,2-Diphenylethane-1,2-diamine (DPEN) in Asymmetric Transfer Hydrogenation of Ketones. Eur. J. Org. Chem. 2011, 6893. (b) Witzig, R. M.; Fäseke, V. C.; Häussinger, D.; Sparr, C. Atroposelective synthesis of Tetra-ortho-substituted Biaryls by Catalyst-controlled Non-canonical Polyketide Cyclizations. Nature Catal. 2019, 2, 925.

(15) Hashiguchi, S.; Fujii, A.; Takehara, J.; Ikariya, T.; Noyori, R. Asymmetric Transfer Hydrogenation of Aromatic Ketones Catalyzed by Chiral Ruthenium(II) Complexes. J. Am. Chem. Soc. 1995, 117,7562 .

(16) Fujii, A.; Hashiguchi, S.; Uematsu, N.; Ikariya, T.; Noyori, R. Ruthenium(II)-Catalyzed Asymmetric Transfer Hydrogenation of Ketones Using a Formic Acid-Triethylamine Mixture. J. Am. Chem. Soc. 1996, 118, 2521.

(17) Rhyoo, H. Y.; Park, H. J.; Chung, Y. K. The first Ru(II)catalysed asymmetric hydrogen transfer reduction of aromatic ketones in aqueous media. Chem. Commun. 2001, 2064.

(18) Västilä, P.; Zaitsev, A. B.; Wettergren, J.; Privalov, T.; Adolfsson, H. The Importance of Alkali Cations in the $\left[\left\{\mathrm{RuCl}_{2}(\mathrm{p}-\right.\right.$ cymene) 2]-Pseudo- dipeptide-Catalyzed Enantioselective Transfer Hydrogenation of Ketones. Chem. Eur. J. 2006, 12, 3218. 